\title{
ATTENDING TO CONDITIONS THAT FACILITATE INTERCULTURAL COMPETENCE A Reciprocal Service-learning Approach
}

\author{
Rachel M. B. Collopy, Sharon Tjaden-Glass, and Novea A. Mclntosh
}

\section{Abstract}

Although service-learning can support the development of intercultural competence, it has also maintained power differentials, reinforced privileged perspectives, and strengthened deficit thinking. Recent research has investigated the conditions within service-learning associated with positive change in diversity-related attitudes. We extend that work, conceptualizing a reciprocal service-learning (RSL) approach that integrates conditions posited by contact theory and the process model of intercultural competence into servicelearning's core features of reflection and reciprocity. In an RSL approach, transformational reciprocity at the participant level supports cultural awareness, interdependence, and parity between participant groups. We created an RSL experience and measured change in three attitudes fundamental to the development of intercultural competence with quantitative pre-and post-surveys. Results indicate that both participant groups-native English-speaking undergraduate students and international English language learnersexperienced significant growth. This study responds to calls for quantitative pre-and post-research methods and the assessment of outcomes for all service-learning participants.

Intercultural competence is vitally important in pluralistic societies, diverse workplaces, and our highly interconnected world. Because intercultural competence develops through repeated opportunities for cross-cultural interaction and reflection (Deardorff, 2006), service-learning opportunities are particularly suited for this iterative learning process. Service-learning is

a form of experiential education where learning occurs through cycles of action and reflection as students work with others through a process of applying what they are learning to community problems, and at the same time, reflecting upon their experience as they seek to achieve real objectives for the community and deeper understanding for themselves. (Eyler \& Giles, 1999) 
Service-learning has produced mixed results with college student participants. Some studies report a positive impact on college students' intercultural competence (Borden, 2007; Buchanan, Correia, \& Bleicher, 2010; Celio, Durlak, \& Dymnicki, 2011; De Leon, 2014; Rodriguez-Sabater, 2015). However, service-learning also has had unintended outcomes with college students: reifying stereotypes, entrenching deficit thinking, and reinforcing privileged perspectives (Camacho, 2004; Jones, LePeau, \& Robbins, 2013; Skobba \& Bruin, 2016). While results for traditional undergraduates vary, the research literature is silent on intercultural competence-related outcomes for service-learning partners.

Recent research has investigated the conditions under which service-learning promotes positive change in diversity-related attitudes. Direct intergroup contact in service-learning is associated with college students' endorsement of social equality (Brown, 2011; Brown, Wymer, \& Cooper, 2016) and awareness of racial privilege and blatant racism (Conner \& Erickson, 2017). Moreover, these changes are significantly greater when intergroup contact reflects the conditions proposed by contact theory (Allport, 1954; Brown et al., 2016; Conner \& Erickson, 2017). The current quantitative study extends this line of research to attitudes that are foundational to the development of intercultural competence.

This article has three aims. First, we begin by conceptualizing a reciprocal service-learning (RSL) approach that integrates conditions posited by contact theory (Allport, 1954; Pettigrew \& Tropp, 2005) and the process model of intercultural competence (Deardorff, 2006) into service-learning's core features of reflection and reciprocity. Second, using quantitative pre/post measures, we then investigate whether RSL participation significantly affects three attitudes that are foundational to intercultural competence. Third, we respond to the perennial lack of research on outcomes for service-learning partners (Blouin \& Perry, 2009; Bortolin, 2011; Cooks $\&$ Scharrer, 2006) by measuring and reporting outcomes for both participant groups: native English-speaking, undergraduate teacher education students and international English language learners in an intensive English program.

\section{Theoretical Frameworks}

We draw on two established theoretical frameworks to identify conditions likely to facilitate the development of intercultural competence through service-learning. First, contact theory proposed facilitating conditions under which sustained intergroup contact reduces prejudice and intergroup conflict (Allport, 1954). These are equal status within the context of the contact; common goals that require the intergroup contact; the perception that intergroup cooperation or interdependence is needed to attain the goals; and support for the norms of interaction from authorities, laws, or community customs. More than 50 years of research support the combined effect of the conditions (Dovidio, Glick, \& Rudman, 2005). Studies support the efficacy of each of Allport's conditions and note challenges to creating equal status and norms of interaction within service-learning experiences (Brown et al., 2016; Conner \& Erickson, 2017; Fitch, 2005; Tangen, Mercer, Spooner-Lane, \& Hepple, 2011; Tinkler, hannah, \& Tinkler, 2016). A meta-analysis of over 500 studies reports that although intergroup contact generally reduces prejudice, the effect size is markedly higher when contact is structured to meet the facilitating 
conditions (Pettigrew \& Tropp, 2005). In addition to reducing negative preconceptions, embedding each of the facilitating conditions into service-learning can have a positive impact on participants' diversity-related attitudes and intercultural competence (Brown et al., 2016; Conner \& Erickson, 2017; Fitch, 2005; Tangen et al., 2011; Tinkler et al., 2016).

Whereas Allport's contact theory names conditions that facilitate the reduction of prejudice, Deardorff's (2006) process model of intercultural competence describes the elements of intercultural competenceattitudes, knowledge, skills, internal outcomes, and external outcomes—and delineates pathways between these elements during recursive iterations of cross-cultural interaction. Repeated cross-cultural interactions, preferably coupled with reflection, inform internal shifts in frames of reference and external expressions of intercultural communication and behavior. Thus, cross-cultural interactions support changes in attitudes toward culturally diverse others (He, Lundgren, \& Pynes, 2017; Shiri, 2015). Furthermore, post-interaction reflection deepens the development of intercultural competence (Hagar, 2018; Wilbur, 2016). The cycle then repeats with participants' modified personal attitudes as the new starting point.

The process model suggests that the cycles of intergroup contact and reflection must be repeated over time. In addition, the iterations of contact and reflection must facilitate both opportunities for cultural self-awareness and knowledge of the other group's culture. Culture is "the values, beliefs, and norms held by a group of people that shape how individuals communicate and behave" (Deardorff \& Edwards, 2013, p. 161). Deardorff explains that cultural self-awareness is "the essence of cross-cultural knowledge in that it is crucial for individuals to be aware of the way in which they view the world ... experiences of others are often measured against one's own cultural conditioning" (Deardorff, 2006, p. 37). The importance of preservice teachers' cultural self-awareness is documented in a study of 113 Australian preservice teachers who participated in a cross-cultural service-learning experience with Malaysian peers (Tangen et al., 2011). Gaining awareness of their own cultural assumptions and identities was essential to participants' learning about the others' culture and beginning to develop intercultural competence.

Deardorff (2006) emphasizes that "attitude is a fundamental starting point" (p. 255) for individuals who engage in intercultural interactions. Attitudes influence an individual's learning of intercultural knowledge and skills and, in turn, internal and external outcomes. Three requisite attitudes that facilitate the development of intercultural competence are respect, openness, and curiosity. Respect is defined as "valuing other cultures," openness as "withholding judgment," and curiosity as "tolerating ambiguity and uncertainty" (Deardorff, 2006, p. 254). Because of their foundational role in developing intercultural competence, we focus on changes in these requisite attitudes in this study.

\section{Reciprocal Service-learning}

Service-learning that offers repeated iterations of intergroup contact and reflection is an appealing context for the development of intercultural competence. However, service-learning experiences vary greatly in the structure and quality of cross-group contact they afford and do not necessarily offer opportunities to probe cultural 
identities, beliefs, and norms. In this section, we explore how the above-identified conditions intersect with service-learning's essential concepts of reflection and reciprocity. Our purpose is to delineate an approach known as reciprocal service-learning (RSL), which we hypothesize will facilitate intercultural competence development.

Reflection. The learning from service-learning is generated and deepened through structured reflection on the service experience, not because of the experience in itself (Ash \& Clayton, 2009; Eyler \& Giles, 1999). Structured reflection can take many forms including individual or group, written or oral, or activity-based or artistic creations (Eyler, Giles, \& Schmiede, 1996; Jacoby, 2015). Structured group discussions and individually written journals are common methods of engaging students in reflection that connects service-learning experiences with academic content.

Cross-cultural interactions provide fertile ground for "disorienting dilemmas" (Mezirow, 2000) and moments of disequilibrium, surprise, and confusion (Desroches, 2015). Through reflection, participants come to new understandings, potentially challenging the assumptions and stereotypes in their existing worldviews (Chang, Chen, Huang, \& Yuan, 2012; Desroches, 2015; Li \& Lal, 2006). Desroches (2015) illustrates how structured reflection creates a space for self-awareness and inquiring into one's own preconceptions about diverse others. Structured reflection offers opportunities to develop both cultural self-awareness and knowledge of other cultures (Hagar, 2018; Rodriguez-Sabater, 2015). An RSL approach includes both repeated direct person-toperson cross-group experiences designed to reveal cultural identities, values, beliefs, and norms and structured reflection that offers opportunities to process those experiences.

\section{Reciprocity}

Broadly speaking, reciprocity connotes a spirit of partnership between service-learning partners (Galvan \& Parker, 2011). Community and university partners, for example, are jointly involved in the identification of authentic community needs and decisions about the design of service interactions (Jacoby, 2015). Although reciprocity is a threshold concept in service-learning (Harrison \& Clayton, 2012), it has been understood and applied in multiple ways (Dostilio et al., 2012).

Transactional versus transformative. Enos and Morton (2003) distinguish between reciprocity that is embodied in transactional and transformative relationships. Transactional relationships involve a mutually beneficial exchange of goods or services (Dostilio et al., 2012; Saltmarsh, Hartley, \& Clayton, 2009). "Participants give and receive something from the other that they would not otherwise have. Reciprocity is conceived of as the interchange of benefits, resources, or actions” (Dostilio et al., 2012, p. 19). Thus, in transactional relationships, "individuals leave the transaction satisfied with the outcome but not much changed" (Enos \& Morton, 2003).

Transactional reciprocity is ill matched to the objective of fostering intercultural competence. First, personal change is essential to intercultural competence development, yet it is only incidental to transactional reciprocity. Second, transactional relationships can replicate society's status hierarchy and reinforce students' privileged perspectives and positions (Hickmon, 2015; Stewart \& Webster, 2011). Sustaining traditional power dynamics undercuts the essential conditions of equal status and interdependence. As Donahue explains, "Power flows one 
way, from those giving to those receiving; the givers of power attempt to change the values and actions of the receivers of power to make the receivers more like themselves” (Donahue, Bowyer, \& Rosenberg, 2003, p. 15). However, valuing other cultures, withholding judgment, and tolerating ambiguity underlie the development of intercultural competence (Deardorff, 2006). These attitudes can be undermined by inherent power differentials when one partner is positioned as in need of service and the other as the provider of service.

In contrast, transformative reciprocity is characterized by partners with shared aspirations and the possibility of personal growth and change (Enos \& Morton, 2003). Such "thick" reciprocity "emphasizes shared voice and power and insists upon collaborative knowledge construction and joint ownership of work processes and products [and thereby] aligns well with ... democratic approaches to civic engagement [that] encourage all partners to grow and to challenge and support one another's growth" (Jameson, Clayton, \& Jaeger, 2011, p. 264). Transformative reciprocity opens possibilities of norms of interaction that support equal status, common goals, and interdependence.

Institutional versus participant transformation. Much of the discussion of reciprocity has been at the level of institutional partnerships (e.g., Boyle-Baise, 2002; Jacoby \& Associates, 2003). However, intercultural competence develops at the participant level within the context of interpersonal interactions. Thus, an RSL approach embodies transformational reciprocity between individuals rather than between institutions. This conceptualization aligns with Dostilio's influence-oriented reciprocity and d'Arlach's reciprocal exchanges. In influence-oriented reciprocity (Dostilio et al., 2012), participants engage in relationships of reciprocal influence. The diverse perspectives and contexts of participants are honored and, through iterative cycles of interactions, partners jointly influence the process or outcomes of the collaboration. During reciprocal exchanges (d'Arlach, Sánchez, \& Feuer, 2009), knowledge flows bi-directionally between people of different backgrounds and levels of privilege. Reciprocal exchanges have three key elements: deliberate empowerment and value of community members' knowledge; ample time for developing trusting relationships and reflection; and acceptance of the inevitable discomfort that accompanies transformative dialogue.

Reciprocal influence between participants is at the heart of the RSL approach. RSL experiences begin with common or complementary goals that require intergroup contact, cooperation, and mutual interdependence. Each group perceives that they need the other to be successful. For at least one group, if not both, developing intercultural competence is an explicitly stated and intentionally supported goal rather than an incidental outcome. The interactions between partners are deliberately designed to promote parity between partners through a reciprocal flow of knowledge and influence across groups. Partners share equal status as co-educators, co-servers, co-learners, and co-contributors to the goals of the service-learning experience. Moreover, the service-learning facilitators must unambiguously support these norms of equal status and mutual interdependence.

Assessment of reciprocal impact. Too often, a commitment to shared status, reciprocal influence, and valuing of service-learning partners does not extend to the assessment of outcomes. Although several studies have investigated impact on community partners in addition to university partners and participants (e.g., BoyleBaise, 2002; Tinkler \& Tinkler, 2017), research on the impact on community participants is perennially missing (Blouin \& Perry, 2009; Cooks \& Scharrer, 2006). Galvan and Parker (2011) call for investigating service learn- 
ing's reciprocal impact on both groups of participants. Gilbride-Brown (2011) argues that particularly little attention has been given to the outcomes for partners from culturally, socioeconomically, racially, and/or linguistically non-dominant communities. For example, studies have sought to develop the intercultural competence of both domestic and international college students through service-learning but assessed only outcomes for the domestic students (Jon, 2013; Wickline, 2012). Such lopsided attention implies that the outcomes for one group is paramount while the outcomes for the other are peripheral. Reflecting the equal status and value, RSL outcomes are assessed for both groups of participants.

In summary, a reciprocal service-learning approach includes four design elements identified in the above discussion: repeated cycles of intergroup contact that promotes cultural awareness followed by structured reflection; common or complementary goals that require interdependence; norms of interaction that support equal status and mutual interdependence; and assessment of outcomes for both groups of participants.

Next, we describe how we incorporated these design elements into an RSL experience. We then report on quantitative pre- and post-measures to investigate two research questions. First, did the undergraduate college student participants experience positive growth in attitudes fundamental to the development of intercultural competence during the course of the RSL experience? Second, did the community participants, in this case international English language learners, experience positive growth in attitudes fundamental to the development of intercultural competence during the course of the RSL experience? We hypothesized that each group of participants would evidence significant growth in at least one of the three fundamental attitudes.

\section{Methods}

This study was conducted during the fall and spring semesters of a single academic year at a comprehensive private university in the midwestern United States. The service-learning experiences engaged native Englishspeaking undergraduate education majors and international English language learners in conversations and collaborative activities for an hour a week for 10 weeks. The experience served as a required field placement for preservice teachers enrolled in a course on educating learners with diverse needs in the general education classroom. Approximately one-third of the course content was on teaching English language learners. The experience was an extracurricular offering for international students enrolled in an intensive English program. These participants were seeking to improve their English skills so they could seek undergraduate or graduate degrees at English-speaking universities. One of the co-authors taught in the Intensive English Program (IEP), whereas the other two co-authors served as instructors for the teacher education students' course.

Although the two groups of participants studied at the same institution, they represent two distinct communities who infrequently have meaningful contact with each other. International students often select to live separately, thereby reducing the possibility for authentic interactions with domestic peers (Glass \& Braskamp, 2012; Young, 2014). Domestic students, in turn, often do not express interest in interacting with international students (Glass \& Westmont, 2013). The two groups of participants in the study were particularly isolated from each other. Unlike the undergraduates, the international participants in this study had not yet matriculated 
into courses toward a degree but took classes only through the IEP, located within the University's Center for International Programs. The IEP student lounge and classrooms are located in a separate building from those where matriculated students take classes. In addition, IEP students do not live in residence halls with matriculated students but typically live separately off campus. Moreover, IEP instructors had noted that even while their English proficiency improved, many international participants continued to lack the confidence interacting with Americans.

\section{Reciprocal Service-learning Experience}

To enact an RSL experience, we intentionally and explicitly set goals requiring mutual interdependence, promoted the equal status in the orientation session and through the design of activities, provided a fertile context for cultural exploration through interactions and reflection, and assessed the outcomes developing intercultural competence for both groups.

Setting common goals. While education majors needed interactions with English learners to complement their course content, the international participants needed opportunities to converse with native speakers. Developing intercultural competence was a common goal for both groups that required intergroup contact and cooperation.

Supporting norms of equal status and mutual interdependence. The orientation for both groups included fundamental knowledge about intercultural communication, explanation of the RSL approach, and discussion of the two groups' complementary goals and assets. We were aware that many university students frame their service-learning experience through a deficit perspective (Bauer, Kniffen, \& Priest, 2015). We asked students to compare a deficit assumption (e.g., "I'm going to help them because they need my help") with an assumption of interdependence and complementary assets (e.g., "We need help from each other"). We anticipated that at some point conversations may become uncomfortable and participants would have trouble communicating with one another (d'Arlach et al., 2009), therefore orientation included guidance about using follow-up questions grounded in curiosity instead of judgment.

We further supported the norms of parity and interdependence through the structure of activities. Because interactions were in English, the native English speakers began in a relatively privileged position. To mitigate power differentials and promote equal status, we divided participants into small groups, each with more English language learners than native English speakers.

Promoting cultural awareness through intergroup contact and reflection. When members of a dominant group interact infrequently with other groups, they may unknowingly act on the privilege of assuming their worldview as "normal" or "regular" and framing others as "different" or even "exotic." For this reason, it was particularly important for undergraduate participants to engage in activities that would demonstrate that culture does not belong solely to dominant groups (Gorski, 2008). Each week participants began with a group activity or a set of questions as a conversation starter that encouraged participation from all members (cf. TjadenGlass, 2017). Examples of activities included modified versions of Berardo and Deardorff's (2012) Identity Tags 
activity; Bennett's (1977) Description, Interpretation and Evaluation activity; Apedaile and Schill's (2008) Critical Incidents activity; and SALTO-YOUTH Cultural Diversity Resource Centre's (2008) Tower of Babel activity. Early sessions focused on themes of personal identity and exploration of one's own cultural lens and values. Later sessions moved to intercultural group communication and cultural values.

Because of the key role of reflection in both service-learning and the development of intercultural competence, participants engaged with structured questions at the end of each session, drawing connections between their experiences and their cross-cultural skills, knowledge, and attitudes. In addition, undergraduate participants wrote reflective journal entries, and international participants completed reflective writing assignments. These iterative cycles of interaction, followed by reflection, encouraged participants to make meaning of their experience and consciously shift their cultural frames of reference.

Assessing reciprocal impact. As described below, we assessed growth in intercultural competence of both groups of participants, further reflecting their equal status.

\section{Participants}

Each semester, three 10-week service-learning sessions were offered at different meeting times. Undergraduate participants were assigned to meeting times based on their schedules and availability, and their attendance was mandatory. For two of the weekly sessions, international participants committed to attend throughout the semester. Attendance at the third session was on a "drop-in" basis for international students. Because English language learners in the drop-in session did not commit to regular attendance, they were not included in the data collection.

Demographics. Undergraduate participants $(n=33)$ were second- or third-year preservice teachers who completed both a pre- and post-participation surveys. Thirty-two identified as white and one as Asian. Thirty-two were female, and one was male. All were native English speakers. These participants were seeking teacher licensure in early childhood education (16), in middle childhood education (6), in adolescent to young adult education (6), as intervention specialists (4), or in world languages (1).

International participants $(n=22)$ enrolled in the university's intensive English program for non-native English speakers. They met the criteria of regular attendance in the weekly sessions and completion of both preand post-participation surveys. International participants were from China (4), India (2), Japan (4), Kuwait (1), Libya (2), Saudi Arabia 8), and South Korea (1). Eleven were male, and 11 were female.

Prior experience with diversity. A pre-participation survey included seven items adapted from Guyton and Wesche's (2005) Experiences with Diversity Scale to measure the participants' prior experiences with cultural difference. Prior experience in multicultural environments may affect participants' receptivity to cross-cultural experiences and development of intercultural competence (Martin, 1987). Examples include "When I was a child, I played with children who were from different cultures than me" and "In the past, I chose to watch TV shows and movies about people who were from different cultures than me." Participants responded using a 4-point Likert-type scale with values including never, rarely, occasionally, and frequently. Descriptive statistics were computed to measure participants' prior experience with cultural difference. 
Undergraduate teacher education majors reported limited direct prior experiences with people from cultures different from their own. They also had limited prior experience learning about people from other cultures indirectly through books or other media. Their average scores for all items on Guyton and Wesche's Experiences with Diversity Scale fell between rarely and occasionally.

International participants reported severely limited direct prior experiences with people from cultures different from their own. Their scores on average for having had direct interaction with people from other cultures as playmates, classmates, neighbors, and teammates fell between never and rarely. In contrast, international participants on average reported watching TV shows and movies about people from other cultures occasionally to frequently.

\section{Data Collection}

Data was collected through pre- and post-participation surveys. The surveys also included four scales from Chen and Starosta's (2000) Intercultural Sensitivity Scale. Chosen after an extensive literature review, these measured attitudes identified in Deardorff's process model for intercultural competence (2006). Chen and Starosta's Respect of Cultural Differences subscale corresponds with the attitude of respect (e.g., "I respect the ways people from different cultures behave"). The Interaction Engagement subscale matches the attitude of openness (e.g., "I am open-minded to people from different cultures"). The Interaction Enjoyment subscale (e.g., "I get upset easily when interacting with people from different cultures" reverse coded) together with the Interaction Confidence subscale (e.g., "I feel confident when interacting with people from different cultures") reflect the attitudes of curiosity and discovery. The wording of some items was modified to make them comprehensible to English language learners while retaining the original meaning. For example, the phrase "culturally distinct counterpart” was replaced with "people from different cultures." Participants responded using a 5-point Likert-type scale with the values strongly disagree, disagree, uncertain, agree, and strongly agree.

\section{Data Analysis}

Cronbach's alpha was computed to determine the internal consistency of the four subscales from Chen and Starosta's (2000) Intercultural Sensitivity Scale. Finally, repeated-measures $t$ tests were conducted to determine whether attitudes critical to the development of intercultural competence changed significantly for each group of participants.

\section{Results}

Means and standard deviations are reported in Table 1 for participants' prior experiences in multicultural environments. Results of the repeated-measures $t$ test for four dimensions of intercultural competence are reported in Table 2. 
Table 1

Descriptive Statistics: Participants'Prior Multicultural Experience

$n=55$

\begin{tabular}{|c|c|c|c|c|}
\hline & \multicolumn{2}{|c|}{$\begin{array}{l}\text { Undergraduate } \\
\text { education majors } \\
\qquad(n=33)\end{array}$} & \multicolumn{2}{|c|}{$\begin{array}{l}\text { International English } \\
\text { language learners } \\
(n=22)\end{array}$} \\
\hline & $M$ & $S D$ & $M$ & $S D$ \\
\hline $\begin{array}{l}\text { When I was a child, I played with children who were from different } \\
\text { cultures than me. }\end{array}$ & 2.39 & .933 & 1.77 & .922 \\
\hline $\begin{array}{l}\text { When I was a teenager, my classmates were from different cultures } \\
\text { than me. }\end{array}$ & 2.88 & .781 & 1.91 & .868 \\
\hline $\begin{array}{l}\text { When I was a child, there were people in my neighborhood who were } \\
\text { from different cultures than me. }\end{array}$ & 2.21 & 1.111 & 1.91 & 1.065 \\
\hline $\begin{array}{l}\text { As a teenager, I was on the same team and/or club with students who } \\
\text { were from different cultures than me. }\end{array}$ & 2.76 & 1.001 & 2.00 & 1.069 \\
\hline $\begin{array}{l}\text { In the past, I chose to read books about people who were from different } \\
\text { cultures than me. }\end{array}$ & 2.36 & .783 & 2.41 & 1.221 \\
\hline $\begin{array}{l}\text { When I was younger, someone from a different culture was an example } \\
\text { of a person that I wanted to become in the future. }\end{array}$ & 2.21 & .857 & 2.45 & 1.224 \\
\hline $\begin{array}{l}\text { In the past, I chose to watch TV shows and movies about people who } \\
\text { were from different cultures than me. }\end{array}$ & 2.67 & .890 & 3.45 & .858 \\
\hline
\end{tabular}

Table 2

Repeated-measures $t$ test for Four Dimensions of Intercultural Competence: Undergraduate Education Majors $(n=33)$

\begin{tabular}{|c|c|c|c|c|c|c|c|}
\hline & \multicolumn{2}{|c|}{ Pre-Participation } & \multicolumn{2}{|c|}{ Post-Participation } & \multirow[b]{2}{*}{$t$} & \multirow[b]{2}{*}{$d f$} & \multirow[b]{2}{*}{$P$} \\
\hline & M & $S D$ & $M$ & $S D$ & & & \\
\hline Respect for cultural differences & 4.11 & 0.56 & 4.27 & 0.42 & -2.38 & 32 & $0.023^{*}$ \\
\hline Interaction engagement & 3.94 & 0.54 & 4.20 & 0.48 & -3.98 & 32 & $0.000^{* * *}$ \\
\hline Interaction enjoyment & 3.75 & 0.71 & 3.79 & 0.63 & -0.32 & 32 & 0.75 \\
\hline Interaction confidence & 3.36 & 0.81 & 3.63 & 0.69 & -1.97 & 32 & 0.058 \\
\hline
\end{tabular}

${ }^{*} p<.05,{ }^{* *} p<.01,{ }^{* * *} p<.001$

\section{Undergraduate Participants}

For undergraduate participants, all subscales from Chen and Starosta's Intercultural Sensitivity Scale had acceptable levels of internal consistency. The reliability reported for each measure is the average Cronbach's alpha on pre- and post-administrations of the survey. Reliability analysis was carried out on the 6-item Respect of Cultural Differences subscale $(\alpha=.75)$, the 7-item Interaction Engagement subscale $(\alpha=0.82)$, the 3-item Interaction Enjoyment subscale $(\alpha=0.74)$, and the 5 -item Interaction Confidence subscale $(\alpha=0.87)$.

Repeated-measures $t$ tests revealed significant positive growth on two measures of attitudes related to intercultural competence for undergraduate participants $(n=33)$ (see Table 2). Respect of Cultural Differences grew 
Table 3

Repeated-measures $t$ test for Four Dimensions of Intercultural Competence: International English Language Learners $(\boldsymbol{n}=22)$

\begin{tabular}{|c|c|c|c|c|c|c|c|}
\hline & \multicolumn{2}{|c|}{ Pre-participation } & \multicolumn{2}{|c|}{ Post-participation } & \multirow[b]{2}{*}{$T$} & \multirow[b]{2}{*}{$d f$} & \multirow[b]{2}{*}{$P$} \\
\hline & $M$ & $S D$ & $M$ & $S D$ & & & \\
\hline Interaction engagement ( 5 items) & 4.20 & 0.68 & 4.25 & 0.57 & -0.28 & 21 & .78 \\
\hline Interaction confidence & 3.29 & 0.65 & 3.73 & 0.62 & -2.97 & 21 & $.007^{* *}$ \\
\hline
\end{tabular}

significantly from before participation $(M=3.29, S D=0.65)$ to after participation $(M=3.72, S D=0.62) ; t(21)$ $=-2.97, p=0.007$. Interaction Engagement before participation $(M=3.29, S D=0.65)$ and after participation $(M=3.72, S D=0.62) ; t(21)=-2.97, p=0.007$.

\section{International Participants}

For international participants, only the 5-item Interaction Confidence subscale $(\alpha=0.87)$ had an internal consistency level over 0.7. Following an item analysis, two items were dropped from the Interaction Engagement subscale resulting in an acceptable level of internal consistency $(\alpha=0.76)$. This modified 5-item Interaction Engagement subscale was used in the repeated-measures $t$ tests. Further item analysis revealed that even after dropping items from the Respect of Cultural Differences and Interaction Enjoyment subscales, their internal consistency remained below 0.60 .

For international participants, repeated-measures $t$ tests revealed significant growth in Interaction Confidence from before participation $(M=3.29, S D=0.65)$ to after participation $(M=3.73, S D=0.62) ; t(21)=-2.97, p=$ 0.007 (see Table 3). Interaction Engagement, measured using the modified 5-item subscale, was not significant. Changes in scores on the Interaction Enjoyment and Respect of Cultural Differences subscales were not analyzed for international participants due to low internal consistency as discussed above.

\section{Discussion}

Our findings supported the hypotheses of this study. First, over the course of participation in an RSL experience, we found significant positive growth in the two of the three foundational attitudes for intercultural competence of undergraduate student participants. Specifically, undergraduate participants made significant strides in developing attitudes of respect for cultural differences and openness in engaging with people from cultures different from their own. Meanwhile, their growth on the foundational attitude of curiosity and tolerating ambiguity and uncertainty was not significant.

These teacher education majors overwhelmingly were members of the racially and linguistic dominant group within the United States. They reported only limited interactions with people from different cultures prior to 
the study. The RSL experience provided opportunities for them to reexamine their biases, deficit-orientation, and privileged perspective. As one undergraduate education student reflected,

In the past, I may have deemed foreign students as incompetent when they were unable to order their food in English. I would wonder how they were receiving an education from the same college as I, when they could not even speak English. I now know and understand just how much work goes into their learning English. ... I no longer see myself superior. ... I still have room for improvement and I am so grateful for the experience.

Second, international participants grew significantly in their interaction confidence indicating greater tolerance for ambiguity in intercultural interactions. They did not gain significantly on the attitude of openness to other cultures. These findings fit with international participants' reports of prior experiences. While they reported occasionally to frequently choosing to watch media from other cultures, their direct interactions with people from other cultures had been very limited.

In addition to offering preliminary support for the efficacy of RSL to impact participants' intercultural competence, the study contributes to the service-learning literature in several ways. First, the study extends a growing body of research suggesting that integrating the tenets of contact theory (Allport, 1954) positively impacts university student participants' diversity-related attitudes (Brown et al., 2016; Conner \& Erickson, 2017; Fitch, 2005; Tinkler et al., 2016) to the development of intercultural competence of both groups of participantsmatriculated undergraduates and international English learners.

Moreover, the study offers an application of a theoretically grounded conceptual framework for an approach to service-learning that increases participants' intercultural competence and potentially other diversity-related attitudes. The framework was derived from the intersection of contact theory (Allport, 1954) and the process model of intercultural competence (Deardorff, 2006) with service-learning's concepts of reflection and reciprocity. The result was RSL's four design elements:

- repeated cycles of intergroup contact that promote cultural awareness followed by structured reflection;

- common or complementary goals that require interdependence;

- norms of interaction that support equal status and mutual interdependence; and

- assessment of outcomes for both groups of participants.

Central to the RSL approach is a definition of reciprocity as transformational reciprocity at the participant level. It is possible for service-learning partnerships to be transformational at the institutional level yet remain transactional at the participant level. Transformational participant-level reciprocity promotes the bi-directional flow of influence and knowledge and recognizes the assets of community participants (d'Arlach et al., 2009; Dostilio et al., 2012). In doing so, it affords space for probing cultural self-awareness and deepening understandings of other cultures, disrupting privilege perspectives, and creating interdependence and equal status between 
participants. A shift from mutuality to reciprocity (Saltmarsh et al., 2009) at the participant level necessitates reframing of the roles of participants, blurring "the distinctions among those who are 'servers' and those who are 'served"' (Wade, 2000).

The current study extended equal status within the service-learning experience to the assessment of outcomes of both participant groups. At an institutional level, this spoke to a commitment to partnership and collaboration (Bortolin, 2011). At the participant level, it communicated a clear and tangible underscoring of parity between participant groups.

Our data analysis illustrates complexities involved with using common methods and instruments with linguistically and culturally diverse participants. We made concerted efforts to attend to the international students' language proficiency, attempting to retain meaning while simplifying grammar and vocabulary. However, survey items that are comprehensible linguistically may not translate culturally. Two of the four scales we used to measure foundational attitudes of intercultural competence proved unreliable for international participants.

As with any study, the results should be viewed in light of the study's limitations. First, the generalizability of the study is limited by the fact it was conducted in one service-learning course at one institution. Furthermore, the undergraduate participants were relatively homogeneous: primarily white, female, native-English speaking preservice teachers. This sample reflects the homogeneity within the teaching pool in the United States and Europe (Donlevy, Meierkord, \& Rajania, 2016; Taie \& Goldring, 2017), a population that would especially benefit from opportunities to enhance their intercultural competence.

Second, because the researchers were also course instructors, participants' responses could reflect some social desirability bias. We attempted to minimize bias by not having instructors administer surveys to their own classes and by assuring participants that their participation was voluntary; responses in no way would affect their course grade, and analyses would maintain anonymity.

Third, the duration of the service-learning experience was 10 weeks within a single semester. We do not know if participants' growth in intercultural competence was sustained after the experience or how the impact of the experience would have been different if the service-learning experience had been longer. Although the length of service-learning in itself does not determine its impact (Fitch, 2005), duration affords the creation of conditions that support positive change. Our theoretical base suggests that RSL experiences must provide ample time for repeated cycles of intercultural interaction and reflection, developing trusting relationships, and enacting norms of mutual interdependence and equal status (Allport, 1954; d'Arlach et al., 2009; Deardorff, 2006).

Fourth, the study's findings are also circumscribed by being based on participant self-report data on quantitative surveys. While this study adds to quantitative research on service-learning, analyses of student written and oral reflections along with cross-group evaluations of interactions could have added additional richness and triangulation to the data. For example, we have anecdotal, not systematic, evidence of participants' emotional reactions to their cross-cultural interactions. Further research needs to probe multi-dimensional means of assessing outcomes that reflect the cultural perspectives and communication styles of participants.

Future research is also needed to investigate the interaction of participants' emotions during service-learning experiences and the development of diversity-related attitudes and behaviors. Emotions can be powerful, engen- 
dering resistance to or serving as a catalyst for intercultural learning (Foldy \& Buckley, 2017; Jokikokko, 2016; King, Perez, \& Shim, 2013). When context supports the creation of positive feelings between individuals from different groups, uncertainty, threat, and anxiety are reduced (Pettigrew \& Tropp, 2005). Future research could inform intentional planning for discomfort that accompanies cross-group interaction and build consensus on what constitutes a service-learning experience of "sufficient duration" to engender positive emotions and productive incidents of cultural disequilibrium.

\section{References}

Allport, G. W. (1954). The nature of prejudice. Reading, MA: Addison-Wesley.

Apedaile, S., \& Schill, L. (2008). Critical incidents for intercultural communication: An interactive tool for developing awareness, knowledge, and skills. Edmonton, Alberta, Canada: NorQuest College Intercultural Education Programs. Retrieved from https:/www.norquest.ca/NorquestCollege/media/pdf/centres/intercultural/CriticalIncidentsBooklet.pdf

Ash, S. L., \& Clayton, P. H. (2009). Generating, deepening, and documenting learning: The power of critical reflection in applied learning. Journal of Applied Learning in Higher Education, 1(1), 25-48.

Bauer, T., Kniffen, L. E., \& Priest, K. L. (2015). The future of service-learning and community engagement: Asset-based approaches and student learning in first-year courses. Michigan Journal of Community Service Learning, 22(1), 89-92.

Bennett, M. J. (1993). Towards ethnorelativism: A developmental model of intercultural sensitivity. In R. M. Paige (Ed.), Education for the intercultural experience. Yarmouth, ME: Intercultural Press

Berardo, K., \& Deardorff, D. (2012). Building cultural competence: Innovative activities and models. Sterling, VA: Stylus Publishing.

Blouin, D. D., \& Perry, E. M. (2009). Whom does service-learning really serve? Community-based organizations' perspectives on service-learning. Teaching Sociology, 37(2), 120-135.

Borden, A. W. (2007). The impact of service-learning on ethnocentrism in an intercultural communication course. Journal of Experiential Education, 30(2), 171-183.

Bortolin, K. (2011). Serving ourselves: How the discourse on community engagement privileges the university over the community. Michigan Journal of Community Service Learning, 18(1), 49-58.

Boyle-Baise, M. (2002). Multicultural service learning: Educating teachers in diverse communities. New York, NY: Teachers College Press.

Brown, M. A. (2011). Learning from service: The effect of helping on helpers' social dominance orientation. Journal of Applied Social Psychology, 41(4), 850-871. doi:10.1111/j.1559- 1816.2011.00738.x

Brown, M. A., Wymer, J. D., \& Cooper, C. S. (2016). The counter-normative effects of service-learning: Fostering attitudes toward social equality through contact and autonomy. Michigan Journal of Community Service Learning, 23(1), 37-44.

Buchanan, M. C., Correia, M. G., \& Bleicher, R. E. (2010). Increasing preservice teachers' intercultural aware- 
ness through service-learning. The International Journal of Research on Service-Learning in Teacher Education, 1(1), 1-19. Retrieved from https://ijrslte.journal.library.uta.edu/index.php/IJRSLTE/article/view/8/1

Camacho, M. M. (2004). Power and privilege: Community service learning in Tijuana. Michigan Journal of Community Service Learning, 10(3), 31-42.

Celio, C. I., Durlak, J., \& Dymnicki, A. (2011). A meta-analysis of the impact of service-learning on students. Journal of Experiential Education, 34(2), 164-181.

Chang, W.-W., Chen, C.-H. L., Huang, Y.-F., \& Yuan, Y.-H. (2012). Exploring the unknown: International service and individual transformation. Adult Education Quarterly, 62(3), 230-251.

Chen, G.-M., \& Starosta, W. J. (2000). The development and validation of the Intercultural Sensitivity Scale. Human Communication, 3, 1-15.

Conner, J., \& Erickson, J. (2017). When does service-learning work? Contact theory and service-learning courses in higher education. Michigan Journal of Community Service Learning, 23(2), 53-65. doi:10.3998/ mjcsloa.3239521.0023.204

Cooks, L., \& Scharrer, E. (2006). Assessing learning in community service learning. Michigan Journal of Community Service Learning, 13, 44-55.

d'Arlach, L., Sánchez, B., \& Feuer, R. (2009). Voices from the community: A case for reciprocity in servicelearning. Michigan Journal of Community Service Learning, 16(1), 5-16.

Deardorff, D. K. (2006). Identification and assessment of intercultural competence as a student outcome of internationalization. Journal of Studies in International Education, 10(3), 241-266.

Deardorff, D. K., \& Edwards, K. E. (2013). Framing and assessing students' intercultural competence in service learning. In P. H. Clayton, R. G. Bringle, \& J. A. Hatcher (Eds.), Research on service learning: Conceptual frameworks and assessment (Vol. 2a, pp. 157-183). Sterling, VA: Stylus Publishing.

De Leon, N. (2014). Developing intercultural competence by participating in intensive intercultural learning. Michigan Journal of Community Service Learning, 21(1), 17-30.

Desroches, C. (2015). Shaping service-learning spaces for preservice teachers to experience and learn to teach for diversity. In K. L. Heider (Ed.), Service learning as pedagogy in early childhood Education. Switzerland: Springer.

Donahue, D. M., Bowyer, J., \& Rosenberg, D. (2003). Learning with and learning from: Reciprocity in service learning in teacher education. Equity \& Excellence in Education, 36(1), 15-27.

Donlevy, V., Meierkord, A., \& Rajania, A. (2016). Study on the diversity within the teaching profession with particular focus on migrant and/or minority background. Final report to Directorate-General for Education and Culture of the European Commission. Luxembourg: Publications Office of the European Union. Retrieved from http://publications.europa.eu/resource/cellar/9f27c61d-2ba9-11e6-b616-01aa75ed71a1.0001.01/ DOC_1

Dostilio, L. D., Brackmann, S. M., Edwards, K. E., Harrison, B., Kliewer, B. W., \& Clayton, P. H. (2012). Reciprocity: Saying what we mean and meaning what we say. Michigan Journal of Community Service Learning, $19(1), 17-32$. 
Dovidio, J. F., Glick, P., \& Rudman, L. A. (2005). On the nature of prejudice: Fifty years after Allport. Malden, MA: Blackwell.

Enos, S., \& Morton, K. (2003). Developing a theory and practice of campus-community partnerships. In B. Jacoby \& Associates (Eds.), Building partnerships for service-learning (pp. 20-41). San Francisco, CA: JosseyBass.

Eyler, J., \& Giles, D. E., Jr. (1999). Where's the learning in service-learning? Jossey-Bass Higher and Adult Education Series. San Francisco, CA: Jossey-Bass.

Eyler, J., Giles, D. E., Jr., \& Schmiede, A. (1996). A practitioner's guide to reflection in service-learning: Student voices Eจ reflections. Nashville, TN: Vanderbilt University.

Fitch, P. (2005). In their own voices: A mixed methods approach to studying intercultural service-learning with college students. In S. Root, J. Callahan, \& S. H. Billig (Eds.), Improving service-learning practice: Research on models to enhance impacts (pp. 187-211). Charlotte, NC: Information Age Publishing.

Foldy, E. G., \& Buckley, T. R. (2017). Reimagining cultural competence: Bringing buried dynamics into the light. Journal of Applied Behavioral Science, 53(2), 264-289.

Galvan, C., \& Parker, M. (2011). Investigating the reciprocal nature of service-learning in Physical Education teacher education. Journal of Experiential Education, 34(1), 55-70.

Gilbride-Brown, J. (2011). Moving beyond the dominant: Service-learning as a culturally relevant pedagogy. In T. Stewart \& N. Webster (Eds.), Exploring cultural dynamics and tensions within service-learning (pp. 27-44). Charlotte, NC: Information Age Publishing.

Glass, C. R., \& Braskamp, L. A. (2012). Foreign students and tolerance. Inside Higher Ed. Retrieved from http://www.insidehighered.com/views/2012/10/26/essay-how-colleges-should-respond-racism-against-international-students

Glass, C. R., \& Westmont, C. M. (2013). Comparative effects of belongingness on the academic success and cross-cultural interactions of domestic and international students. International Journal of Intercultural Relations, 38, -106-119. doi:10.1016/j.ijintrel.2013.04.004

Gorski, P. (2008). Good intentions are not enough: A decolonizing intercultural education. Intercultural Education, 19(6), 515-525. doi:10.1080/14675980802568319

Guyton, E. M., \& Wesche, M. V. (2005). The Multicultural Efficacy Scale: Development, item selection, and reliability. Multicultural Perspectives, 7(4), 21-29.

Hagar, T. J. (2018). Role of reflective knowledge in the development of intercultural competence. Journal of Intercultural Communication Research, 47(2), 87-104. doi:10.1080/17475759.2018.1427615

Harrison, B., \& Clayton, P. H. (2012). Reciprocity as a threshold concept for faculty who are learning to teach with service-learning. Journal of Faculty Development, 26(3), 29-33.

He, Y., Lundgren, P., \& Pynes, K. (2017). Impact of short-term study abroad program: Inservice teachers' development of intercultural competence and pedagogical beliefs. Teaching and Teacher Education, 66, 147-157.

Hickmon, G. (2015). Double consciousness and the future of service-learning. Michigan Journal of Community Service Learning, 22(1), 86-88. 
Jacoby, B. (2015). Service-learning essentials: Questions, answers, and lessons learned. San Francisco, CA: JosseyBass.

Jacoby, B., \& Associates (2003). Building partnerships for service-learning. Francisco, CA: Jossey-Bass.

Jameson, J. K., Clayton, P. H., \& Jaeger, A. J. (2011). Community-engaged scholarship through mutually transformative partnerships. In L. M. Harter, J. Hamel-Lambert, \& J. L. Millesen (Eds.), Participatory partnerships for social action and research (pp. 259-277). Dubuque, IA: Kendall Hunt.

Jokikokko, K. (2016). Reframing teachers' intercultural learning as an emotional process. Intercultural Education, 27(3), 217-230.

Jon, J.-E. (2013). Realizing internationalization at home in Korean higher education. Journal of Studies in International Education, 17(4), 455-470.

Jones, S. R., LePeau, L. A., \& Robbins, C. K. (2013). Exploring the possibilities and limitations of servicelearning: A critical analysis of college student narratives About HIV/AIDS. The Journal of Higher Education, $84(2), 213-238$.

King, P. M., Perez, R. J., \& Shim, W. (2013). How college students experience intercultural learning: Key features and approaches. Journal of Diversity in Higher Education, 6(2), 69-83.

Li, X., \& Lal, S. (2006). Critical reflective thinking through service-learning in multicultural teacher education. Intercultural Education, 16(3), 217-234.

Martin, J. N. (1987). The relationship between student sojourner perceptions of intercultural competencies and previous sojourn experience. International Journal of Intercultural Relations, 11(4), 337-355.

Mezirow, J. (2000). Learning as transformation: Critical perspectives on a theory in progress. San Francisco, CA: Jossey-Bass.

Pettigrew, T. F., \& Tropp, L. R. (2005). Allport's intergroup contact hypothesis: Its history and influence. In J. F. Dovidio, P. Glick, \& L. A. Rudman (Eds.). On the nature of prejudice: Fifty years after Allport (pp. $262-$ 277). Malden, MA: Blackwell.

Rodriguez-Sabater, S. (2015). Service-learning and intercultural competence in the Spanish as a second language classroom. The Southern Journal of Linguistics, 39(1), 1-23.

Saltmarsh, J., Hartley, M., \& Clayton, P. H. (2009). Democratic engagement white paper. Boston, MA: New England Resource Center for Higher Education.

SALTO-YOUTH Cultural Diversity Resource Centre. (2008). Intercultural communication resource pack. London: Author. Retrieved from https://bit.ly/2RJK6uD

Shiri, S. (2015). Intercultural communicative competence development during and after language study abroad: Insights from Arabic. Foreign Language Annals, 48(4), 541-569.

Skobba, K., \& Bruin, M. J. (2016). Examining public housing stereotypes and building intercultural competence through service-learning. Family and Consumer Sciences Research Journal, 44(4), 345-359.

Stewart, T., \& Webster, N. (2011). Exploring cultural dynamics and tensions within service-learning. Charlotte, NC: Information Age Publishing.

Taie, S., \& Goldring, R. (2017). Characteristics of public elementary and secondary school teachers in the United 
States: Results from the 2015-16 national teacher and principal survey. First look (NCES 2017-072). U.S. Department of Education. Washington, DC: National Center for Education Statistics. Retrieved from https://nces.ed.gov/pubs2017/2017070.pdf

Tangen, D., Mercer, K. L., Spooner-Lane, R., \& Hepple, E. (2011). Exploring intercultural competence: A service-learning approach. Australian Journal of Teacher Education, 36(11). doi:10.14221/ajte.2011v36n11.2 Tinkler, B., hannah, c. 1., \& Tinkler, A. (2016). Using contact theory to examine a service-learning experience in a social foundations course. Multicultural Education, 24(1), 31-36.

Tinkler, A., \& Tinkler, B. (2017). Community conversations shape reciprocal partnerships for social justice: A case study of a comprehensive service-learning initiative in a teacher education program. The International Journal of Research on Service-Learning in Teacher Education, 5, 1-12.

Tjaden-Glass, S. (2017). A handbook and materials for iLEAD: An intercultural communication program between Intensive English Program and teacher education students. Dayton, $\mathrm{OH}$ : Center for International Programs Publications and Presentations. Retrieved from https://ecommons.udayton.edu/cip_pub/3

Wade, R. C. (2000). Service-learning for multicultural teaching competency: Insights from the literature for teacher educators. Equity $\sigma^{\circ}$ Excellence in Education, 33(3), 21-29.

Wickline, V. B. (2012). The Crossing Borders program: Increasing intercultural competency via structured social interactions. Psychology Learning Ev Teaching, 11(3), 374-381.

Wilbur, G. (2016). The staying power of intercultural learning through reflective inquiry. Reflective Practice, 17(1), 59-71. doi:10.1080/14623943.2015.1123687

Young, N. E. (2014). Seeking best practices for integrating international and domestic students. Minneapolis, MN: University of Minnesota. Retrieved from https:/global.umn.edu/icc/ documents/14_integration_best_ practices_overall.pdf

\section{Authors}

RACHEL M. B. COLLOPY earned her PhD from the Combined Program in Education and Psychology at the University of Michigan, Ann Arbor. She is an Associate Professor of Teacher Education at the University of Dayton, where she creates opportunities for teacher candidates to explore connections between their own beliefs and identities, classroom practices, and persistent systemic inequities. Her scholarship centers on the preparation of teachers to work with a diversity of learners.

SHARON TJADEN-GLASS, MA TESOL, is an instructional media designer in the eLearning Division of Sinclair Community College in Dayton, Ohio. She is currently the co-editor of InterCom, the newsletter for TESOL International's Intercultural Communication Interest Section. Her research interests are instructional design, elearning for second language learners, and the intersection of second language listening and intercultural communication. 
NOVEA A. McINTOSH, EdD, is an Assistant Professor, Coordinator of the Adolescent to Young Adult program and Co-director of the Urban Teacher Academy in the School of Education and Health Sciences at the University of Dayton. Her teaching and scholarship focus on culturally responsive pedagogy and formative assessment of diverse students. She presents at conferences and provides professional development to in-service and preservice teachers in areas of culturally responsive pedagogy, diversity, and assessment both nationally and internationally. 